\title{
Structural Analyses of Methyl Bicyclobutane-1-carboxylate Oligomers Formed with tert-Butyllithium/Aluminum Bisphenoxide and Mechanistic Aspect of the Polymerization
}

\author{
Takehiro Kawauchi, ${ }^{1, \dagger}$ Maiko NaKamura, ${ }^{1}$ Tatsuki Kitayama,,${ }^{1, \dagger}$ \\ Anne Buyle PADIAS, ${ }^{2}$ and Henry K. HALl, Jr. ${ }^{2}$ \\ ${ }^{1}$ Department of Chemistry, Graduate School of Engineering Science, Osaka University, \\ Machikaneyama-cho, Toyonaka 560-8531, Japan \\ ${ }^{2}$ Department of Chemistry, University of Arizona, Tucson, Arizona 85721, U.S.A.
}

(Received February 3, 2005; Accepted March 7, 2005; Published June 15, 2005)

\begin{abstract}
Anionic polymerization of methyl bicyclobutane-1-carboxylate (MBCB) with tert-butyllithium $\left(t\right.$-BuLi)/bis(2,6-di-tert-butylphenoxy)ethylaluminum $\left[\mathrm{EtAl}(\mathrm{ODBP})_{2}\right]$ in toluene at $-78^{\circ} \mathrm{C}$ gives transtactic polymers (trans contents $>90 \%$ ) with high yields, but with low initiator efficiency and broad molecular weight distribution. In order to obtain information on the initiation mechanism, oligomers of MBCB were prepared with $t$-BuLi/EtAl$(\mathrm{ODBP})_{2}$ in toluene at $-78^{\circ} \mathrm{C}$, and fractionated into dimer to pentamer by size exclusion chromatography. The dimer fraction was further subjected to recycling SEC and found to consist of two types of dimers of different chemical structures. ${ }^{1} \mathrm{H}$ NMR analyses of the dimers revealed that one type of the dimer comprises of an initiating tert-butyl $(t$-Bu) group and two MBCB units while the other contains one $t$-Bu carbonyl group within the monomeric units in addition to the initial $t$-Bu group. Based on the NMR spectroscopic information on the oligomers, ${ }^{1} \mathrm{H}$ NMR spectra of the polymer was investigated with the focus on the end-group structures, that confirms that the carbonyl addition of $t$-BuLi to MBCB occurred and the ketonic compound thus formed participates in the polymerization.
\end{abstract}

[DOI 10.1295/polymj.37.439]

KEY WORDS Transtactic 1,3-Cyclobutane Polymer / Initiation Mechanism / Stereospecific Anionic Polymerization / Chain-end Analysis / NMR spectroscopy / Carbonyl Addition /

Bicyclobutanes carrying electron-withdrawing substituents at 1 - and/or 3-positions are a remarkable class of reactive monomers. ${ }^{1}$ Either free radical or anionic polymerization occurs readily across the $\pi$ like 1,3-bond to give high molecular weight polymers consisting of 1,3-linked cyclobutane rings in the main chain. ${ }^{1}$ Such polymers have interesting properties including high glass transition temperatures, chemical and thermal stability, superior optical clarity, and resistance to depolymerization.

1,3-Disubstituted cyclobutanes exist as either cisor trans-isomers. Accordingly the stereochemistry of the polybicyclobutanes becomes of interest, particularly for its influence on physical properties. Free radical polymerization of dimethyl bicyclobutane-1,3-dicarboxylate gives $95 \%$ trans-linkages. ${ }^{2}$ Similar polymerizations of various 1-monoesters give polymers with trans/cis ratio of about $2 / 1 .^{3}$

Anionic polymerization offers potentially better control of stereochemistry of polymers, but early attempts for methyl bicyclobutane-1-carboxylate (MBCB) with $n$-butyllithium as an initiator gave only low molecular weight products. In the previous paper, ${ }^{4}$ we reported the anionic polymerization of MBCB with tert-butyllithium ( $t$-BuLi)/bis(2,6-di-tertbutylphenoxy)ethylaluminum $\left[\mathrm{EtAl}(\mathrm{ODBP})_{2}\right]$ in toluene at $-78^{\circ} \mathrm{C}$ gave transtactic polymers (trans contents $>90 \%$ ) in high yields. This kind of favorable effect of aluminum bisphenoxides on the anionic polymerization has been well demonstrated in stereospecific living polymerizations of methacrylates and acrylates. ${ }^{5-14}$ However, the given poly(MBCB) had broad molecular weight distribution $\left(M_{\mathrm{w}} / M_{\mathrm{n}} \sim 2\right)$ and the initiator efficiency was low (less than 0.3), implying the possible side reactions.

In order to obtain information on the polymerization of MBCB, with the focus on the initiation mechanism, oligomers of MBCB were synthesized with $t$ $\mathrm{BuLi} / \mathrm{EtAl}(\mathrm{ODBP})_{2}$ in toluene at $-78^{\circ} \mathrm{C}$, fractionated in terms of their degree of polymerization by size exclusion chromatography (SEC), and each fraction was characterized by NMR spectroscopy. The oligomers were found to contain the monomeric unit derived from bicyclobutan-1-yl tert-butyl ketone, a product

\footnotetext{
Present Address: Yashima Super-structured Helix Project, ERATO, JST, 101 Creation Core Nagoya, 2266-22 Moriyama-ku, Nagoya 463-0003, Japan

${ }^{\dagger \dagger}$ To whom correspondence should be addressed (E-mail: kitayama@chem.es.osaka-u.ac.jp).
} 


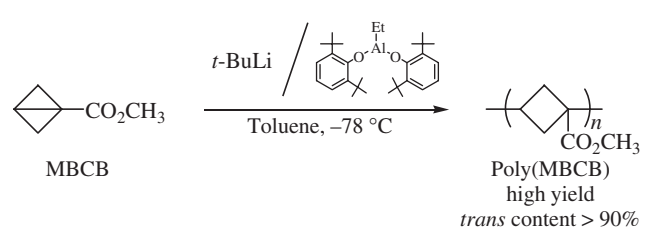

Scheme 1. Stereospecific anionic polymerization of MBCB.

of carbonyl attack of $t$-BuLi to MBCB. Based on the NMR spectral information, the structures of the polymers were also minutely investigated with the emphasis on the occurrence of the side reaction.

\section{EXPERIMENTAL}

\section{Measurements}

NMR spectra were recorded on a Varian Unity Inova 500 NMR spectrometer in chloroform- $d$ (500 $\mathrm{MHz}$ for ${ }^{1} \mathrm{H}, 125 \mathrm{MHz}$ for ${ }^{13} \mathrm{C}$ ). ${ }^{1} \mathrm{H}$ NMR chemical shifts values were referred to the resonance at 7.24 ppm due to residual chloroform in the solvent. Chemical shifts in ${ }^{13} \mathrm{C}$ NMR spectra were referred to the signal due to chloroform- $d$ at $77.0 \mathrm{ppm}$. Heteronuclear multiple-quantum coherence (HMQC) experiments were conducted in chloroform- $d$ at $35^{\circ} \mathrm{C}$ employed a recycle time of $3 \mathrm{~s}$, with four transients being collected for each $t_{1}$ value. The spectra were recorded with a spectral width of $6249.5 \mathrm{~Hz}$ in the F1 dimension $\left({ }^{13} \mathrm{C}\right)$ and $1760.9 \mathrm{~Hz}$ in the $\mathrm{F} 2$ dimension $\left({ }^{1} \mathrm{H}\right)$. A total of $512 t_{1}$ increments (4 transients, 4096 points) were acquired for each $2 \mathrm{D}$ data set and the matrix was zero-filled to a final size $2048 \times 4096$. A window function of Gaussian type was applied to the FIDs prior to Fourier transformation.

Recycle SEC was carried out at room temperature on a system composed of a Jasco model PU-986 pump, a Jasco model HV-992-01 selection unit, a Jasco model RI-1530 reflective index detector, a Rheodyne injector provided with a $1 \mathrm{~mL}$ sample loop (Cotati, CA), and two Shodex SEC columns [K-2001 $(300 \mathrm{~mm} \times 8 \mathrm{~mm})]$ (Tokyo, Japan). Chloroform was used as an eluent at a flow rate of $2.5 \mathrm{~mL} / \mathrm{min}$.

Mass spectra were recorded on a JEOL MSDX303HF mass spectrometer.

\section{Materials}

Methyl bicyclobutane-1-carboxylate (MBCB) was prepared according to the procedures reported previously, ${ }^{3,15}$ and purified prior to polymerization by distillation over calcium dihydride under reduced nitrogen pressure. Toluene and heptane were purified in the usual manner, mixed with a small amount of $n$-butyllithium and distilled under high vacuum just before use. $t$-BuLi in pentane (Aldrich) was used as a heptane solution by replacing the solvent under vacuum. The concentration was determined by titration with butan-2-ol using $o$-phenanthrolin as an indicator. ${ }^{16}$ 2,6Di-tert-butylphenol, obtained commercially (Tokyo Chemical Industry Co., Ltd., Japan), was fractionally distilled, and used as a heptane solution. Triethylaluminum, obtained commercially (Kishida Chemical Co., Ltd., Japan), was used as received. Bis(2,6-ditert-butylphenoxy)ethylaluminum [EtAl(ODBP $\left.)_{2}\right]$ was prepared from 2,6-di-tert-butylphenol and triethylaluminum in heptane at room temperature, according to the literature, ${ }^{6,17}$ recrystallized from heptane, and used as a toluene solution.

\section{Oligomerization and Polymerization}

The oligomerization was carried out in glass ampules filled with dried nitrogen which was passed through Molecular Sieves $4 \mathrm{~A}$ cooled at $-78^{\circ} \mathrm{C}$. To a toluene $(20 \mathrm{~mL})$ solution of $\mathrm{EtAl}(\mathrm{ODBP})_{2} \quad(3.33$ mmol), a heptane solution of $t$-BuLi $(1.67 \mathrm{mmol})$ was added at $-78^{\circ} \mathrm{C}$, and the reaction was initiated by adding MBCB $(0.55 \mathrm{~mL}, 5 \mathrm{mmol})$. The reaction was terminated after $1 \mathrm{~h}$ by adding methanol containing $\mathrm{HCl}$. The reaction mixture was concentrated to dryness under reduced pressure, and the residue was dissolved in chloroform. Insoluble inorganic materials were extracted with water, and the product was recovered by evaporating the solvent.

The anionic polymerizations were carried out in glass ampules filled with dried nitrogen which was passed through Molecular Sieves 4A cooled at $-78^{\circ} \mathrm{C}$. To aluminum bisphenoxide $(0.21 \mathrm{mmol})$ in toluene $(1 \mathrm{~mL})$ was added a heptane solution of $t$-BuLi $(0.07 \mathrm{mmol})$ at the polymerization temperature, and the reaction was initiated by adding MBCB $(2 \mathrm{mmol})$. The reaction was terminated after $24 \mathrm{~h}$ by adding methanol containing $\mathrm{HCl}$. The reaction mixture was concentrated to dryness under reduced pressure, and the residue was dissolved in chloroform. Insoluble inorganic materials were extracted with water, and the product was recovered by evaporating the chloroform under vacuum.

\section{RESULTS AND DISCUSSION}

\section{Oligomerization}

Oligomerization of $\mathrm{MBCB}$ was carried out with a combination of $t \mathrm{BuLi}$ and $\mathrm{EtAl}(\mathrm{ODBP})_{2}$ at a molar ratio of $[\mathrm{MBCB}]:[t-\mathrm{BuLi}]:\left[\mathrm{EtAl}(\mathrm{ODBP})_{2}\right]=2: 1: 3$ in toluene at $-78^{\circ} \mathrm{C}$. The reaction proceeded quantitatively to give a product, whose number-average molecular weight $\left(M_{\mathrm{n}}\right)$ was 2200 and the trans content was $90 \%$. Figure 1a shows an SEC trace of the whole reaction product. Though a considerable quantity of polymeric product was formed, the oligomeric products were fractionated into three fractions, A, B and 


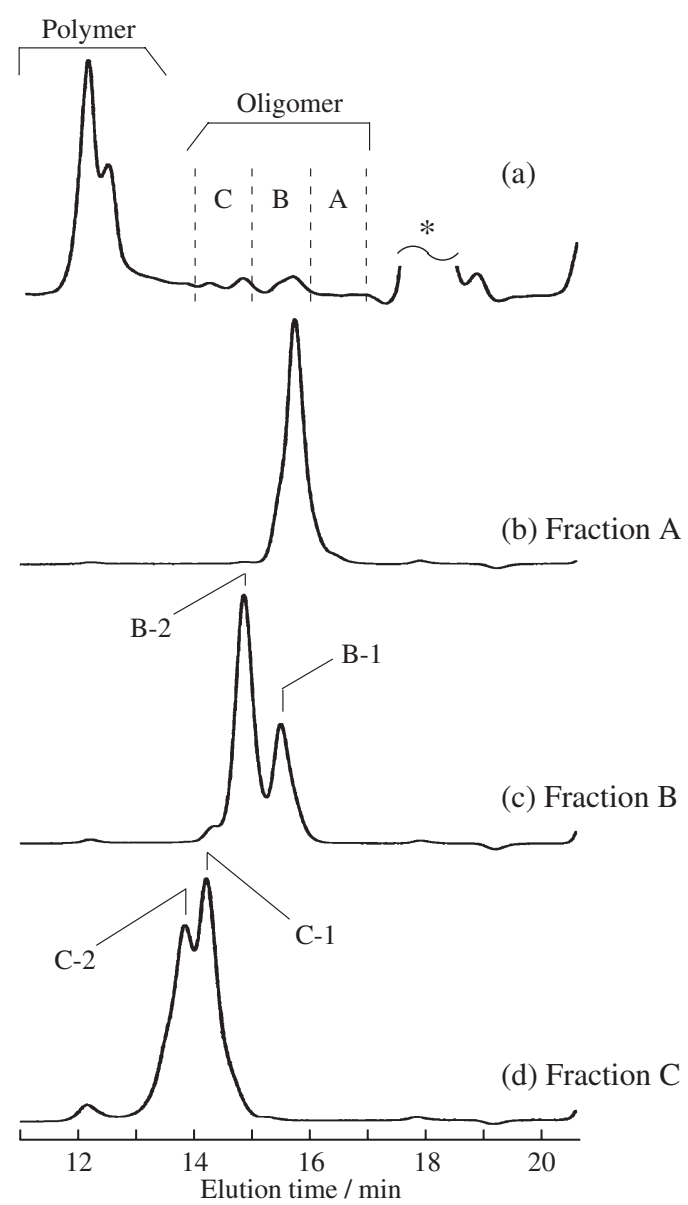

Figure 1. SEC curves of reaction products (a) prepared with $t$-BuLi/EtAl(ODBP $)_{2}(1 / 3)$ in toluene at $-78^{\circ} \mathrm{C}$ for $1 \mathrm{~h}$ and fraction A (b), fraction B (c), fraction C (d) isolated therefrom. *The peak (overscaled) due to 2,6-di-tert-butylphenol from EtAl$(\mathrm{ODBP})_{2}$.

$\mathrm{C}$, as shown in the figure. Figures $1 \mathrm{~b}-\mathrm{d}$ show the SEC curves of these fractions. The fraction $\mathrm{A}$, which showed a seemingly unimodal SEC curve (Figure 1b), was further subjected to recycle SEC measurement (Figure 2). After ten times of recycling, the peak split into two peaks, and the fractions A1 and A2 shown in the figure were collected and subjected to ${ }^{1} \mathrm{H}$ NMR analyses.

\section{Structures of Dimers}

Structure of Fraction A1. Figure 3a shows the ${ }^{1} \mathrm{H}$ NMR spectrum of fraction A1. From chemical shifts and peak splitting patterns, the strong singlet signal at $0.77 \mathrm{ppm}$ and signals around $3.6-3.7 \mathrm{ppm}$ were assigned, respectively, to the $t$-Bu group of the initiating chain-end and methoxy group protons $\left(\mathrm{OCH}_{3}\right)$. Fraction A1 was identified as the dimer from the following argument, whose structure is depicted in the figure. The signal intensity ratio of $t-\mathrm{Bu}: \mathrm{OCH}_{3}$ is $9: 6$, indicating the presence of one $t$ - $\mathrm{Bu}$ group and two $\mathrm{MBCB}$ units. The mass spectrum (chemical ionization meth-

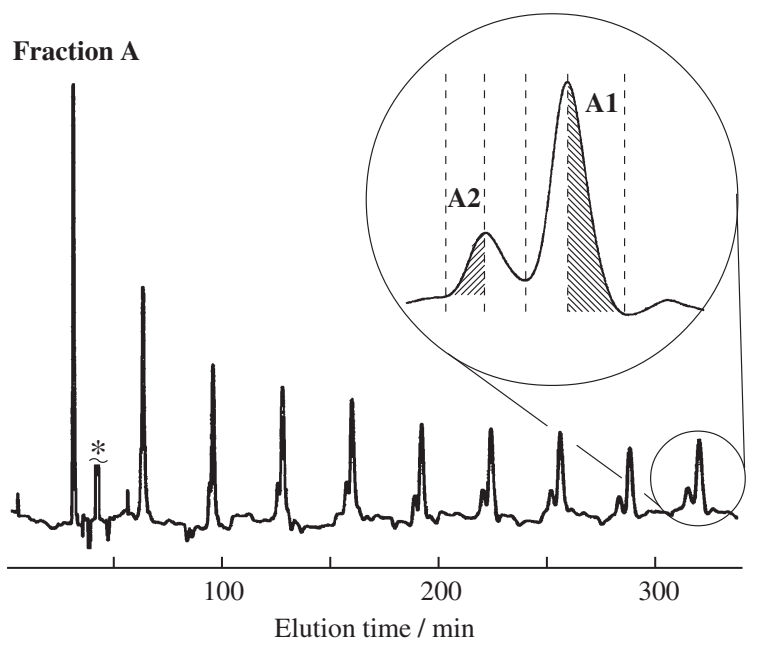

Figure 2. Recycled SEC curves of fraction A in Figure 1. *The peak due to 2,6-di-tert-butylphenol from $\operatorname{EtAl}(\mathrm{ODBP})_{2}$.

(b) Fraction A2

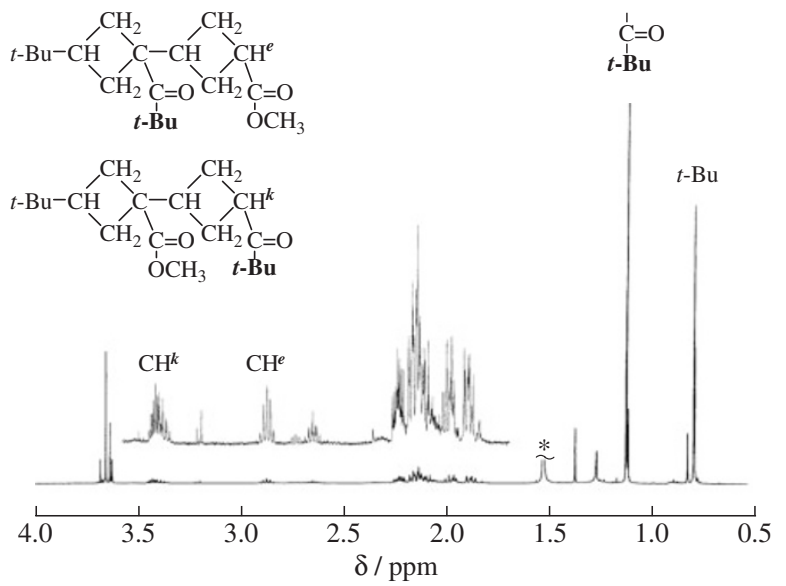

(a) Fraction $\mathrm{A} 1$

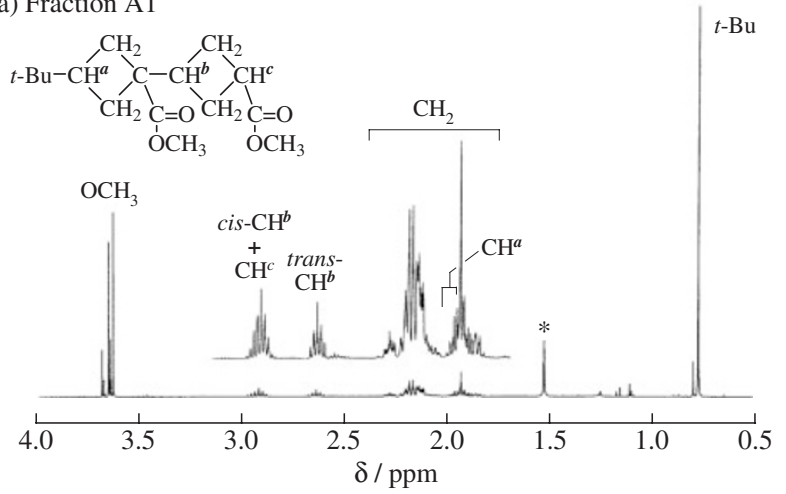

Figure 3. ${ }^{1} \mathrm{H}$ NMR spectra of fractions $\mathrm{A} 1$ (a) and $\mathrm{A} 2$ (b). *The signal due to residual water.

od) of fraction A1 shows a peak at $m / z=282$. These data indicate that fraction $\mathrm{A} 1$ is a dimer of $\mathrm{MBCB}$ with one $t$-Bu group at the chain end. Multiplet signals assignable to $\mathrm{CH}$ protons are observed at 2.64 and $2.92 \mathrm{ppm}$. The signal intensity ratio of $t$-Bu: $\mathrm{CH}(2.64$ ppm): $\mathrm{CH}(2.92 \mathrm{ppm}): \mathrm{OCH}_{3}$ is 9:0.8:1.2:6. The split- 


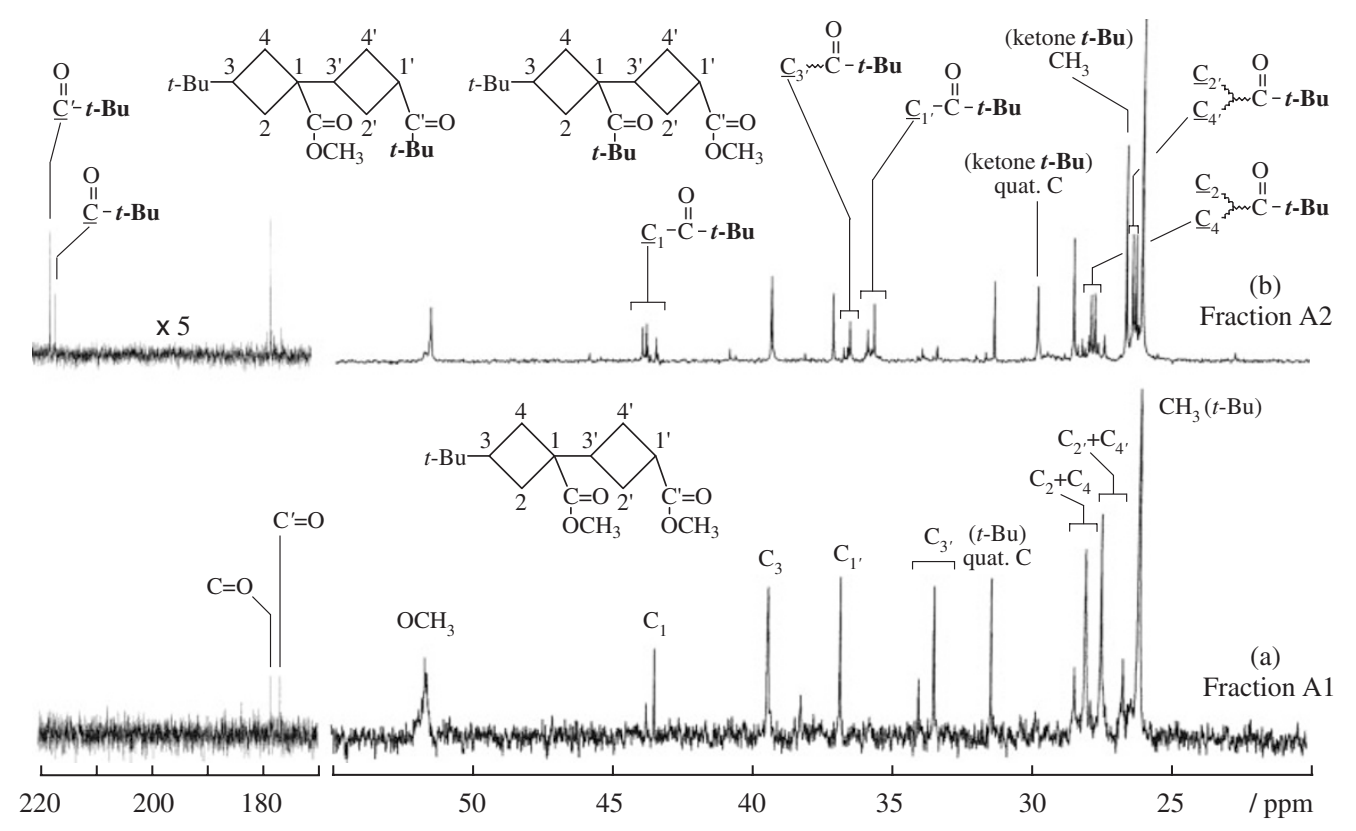

Figure 4. ${ }^{13} \mathrm{C}$ NMR spectra of fractions $\mathrm{A} 1$ (a) and A2 (b). *A line broadening of $2 \mathrm{~Hz}$ was applied to the FID prior to Fourier transformation.

ting pattern of the multiplet signal at $2.92 \mathrm{ppm}$ is nonsymmetric and its relative intensity exceeds unity (1.2). It is considered that the multiplet signal at $2.92 \mathrm{ppm}$ is the overlap of the methine proton in the terminal chain-end $\left(\mathrm{CH}^{c}\right)$ and another methine proton $\left(\mathrm{CH}^{b}\right)$ in the cyclobutane ring of the second unit with cis configuration, the minor constituent. Another multiplet signal (2.64 ppm) could be assigned the methine proton $\left(\mathrm{CH}^{b}\right)$ in trans unit. Further discussion on the cis-trans isomerism of the dimer is described in the next section. Figure 4 a shows the ${ }^{13} \mathrm{C}$ NMR spectrum of fraction A1. The assignments of signals in the figure were made by HMQC measurement.

Structure of Fraction A2. Figure $3 \mathrm{~b}$ shows the ${ }^{1} \mathrm{H}$ NMR spectrum of fraction A2. Two types of strong signals are observed at around 0.7 and $1.1 \mathrm{ppm}$, the latter of which is not observed in the spectrum of fraction A1. Since the ${ }^{13} \mathrm{C}$ NMR spectrum of fraction A2 shows the signal at around $216 \mathrm{ppm}$ (Figure 4b), which is characteristic to ketonic carbonyl carbon, the signal at $1.1 \mathrm{ppm}$ can be assigned to $t$-Bu protons of a ketone structure. The results suggest that the carbonyl addition of $t$-BuLi to MBCB occurred and the ketonic compound thus formed, bicyclobutan-1-yl tert-butyl ketone, participated in the oligomerization (Scheme 2). The ratio of the initiating chain-end $t$ $\mathrm{Bu}$ signal and the ketone structure $t$ - $\mathrm{Bu}$ signal is $1: 1$.

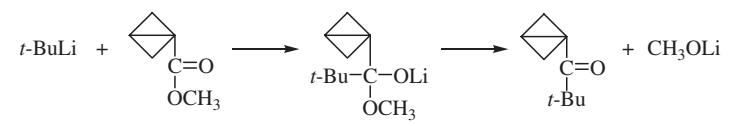

Scheme 2. Carbonyl addition of $t$-BuLi to MBCB.
Therefore, the fraction A2 is identified as a dimer containing one ketone unit. The mass spectrum (chemical ionization method) of fraction A2 showed a parent peak at $m / z=308$, confirming that the dimer contains one ketone unit. Moreover, the multiplet signals are observed at around $3.4 \mathrm{ppm}$, which can be assigned to the methine proton of the terminal chain-end of ketone structure $\left(\mathrm{CH}^{k}\right)$ from their chemical shift. Since the spectrum also shows the signals due to methine protons in the terminal ester unit $\left(\mathrm{CH}^{e}\right)$, the fraction A2 contains the dimers with one ketone unit in the first or second unit, as shown in the figure. Figure $4 \mathrm{~b}$ shows the ${ }^{13} \mathrm{C}$ NMR spectrum of fraction $\mathrm{A} 2$. The detailed assignments indicated in the figure were made by HMQC, which are shown in Figure 5.

\section{Stereoisomers of Dimers}

Stereoisomers in Fraction A1. Owing to cis-trans isomerism in the cyclobutane rings of the dimer, four kinds of stereoisomers are possible as illustrated in Scheme 3. In addition to $E, Z$-nomenclature, the isomers are also named as trans-trans, trans-cis, cistrans and cis-cis by analogy of the polymer chain structure by assuming that the chain starts from the initiating chain-end $t$-Bu group and ends at the terminal methine proton. As seen in Figure 6, the ${ }^{1} \mathrm{H}$ NMR signals of the $t$-Bu and $\mathrm{CH}_{3} \mathrm{O}$ protons exhibit splitting due to such stereoisomerism. The $t$-Bu signals split principally into two groups of peaks, reflecting stereoisomerism within the cyclobutane ring in the first unit, to which the $t$-Bu group attaches. Since the polymerization reaction is trans-specific, the strong signal at the higher magnetic field can be assigned to the 

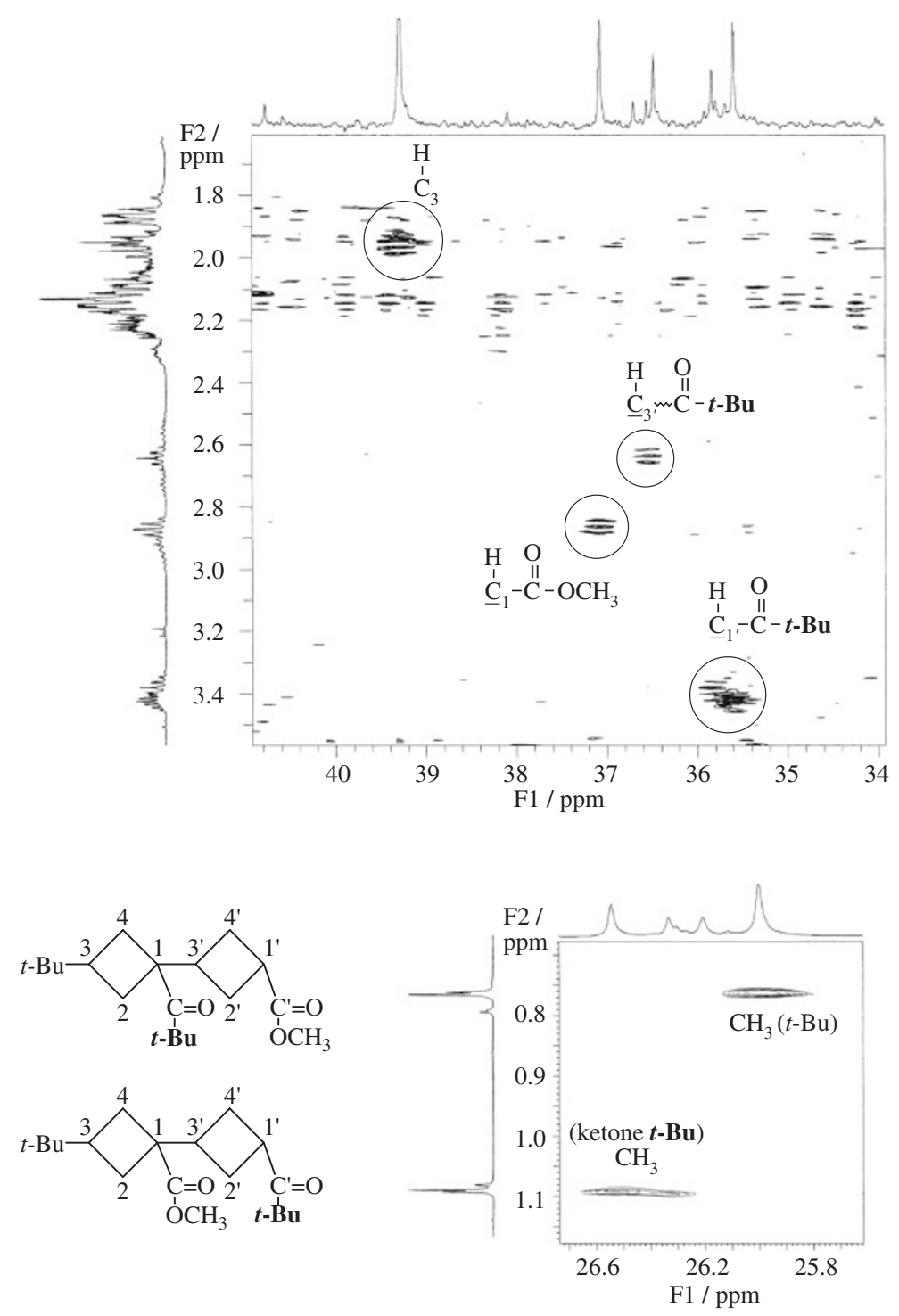

Figure 5. HMQC spectra of fraction A2.

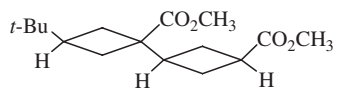

trans-trans $(Z-Z)$

[69\%]

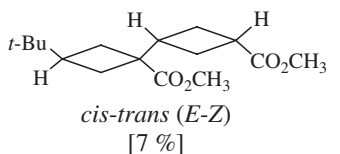

[7\%]

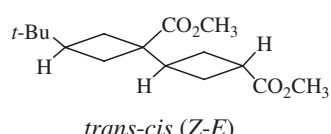

[23\%]

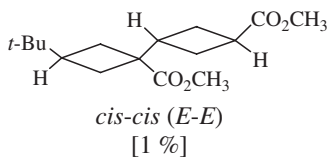

[1\%]

Scheme 3. Four possible stereoisomers (E,Z-nomenclature) [abundance of isomers calculated from signal intensities of $\mathrm{OCH}_{3}$ ].

$t$-Bu group in the trans unit, and another signal to $c i s$ unit. The relative ratio of trans to cis signals is $92 / 8$, which indicates that the polymerization is highly trans-specific even in the initiation process.

The $\mathrm{CH}_{3} \mathrm{O}$ signals of the dimer consist of four sets of paired peaks due to the four kinds of stereoisomers. Though direct NMR assignments of these signals have

been difficult, the assignments are plausible as shown in the figure based on the high trans content of the first monomer unit as well as the trans-specific nature of this polymerization. The ratio of four stereoisomers in fraction $\mathrm{A} 1$ is calculated from the $\mathrm{OCH}_{3}$ signal intensities, as shown in Scheme 3. From these values, trans contents in the first and second monomeric units are estimated as 92 and $76 \%$, respectively. The lower value for the second unit is due to lower trans selectively in protonation reaction, through which the configuration of the second unit is fixed.

Stereoisomers in Fraction A2. In fraction A2, it is necessary to consider the positional isomerism of the ketone structure other than the cis-trans isomerism. Thus, eight isomers can be considered (Scheme 4). Figure 7 shows the expanded $t$-Bu group signals in the ${ }^{1} \mathrm{H}$ NMR spectra of fraction A2. The initiating chain-end signals $(0.79-0.82 \mathrm{ppm})$ split into two principal groups of peaks, reflecting cis-trans isomerism 


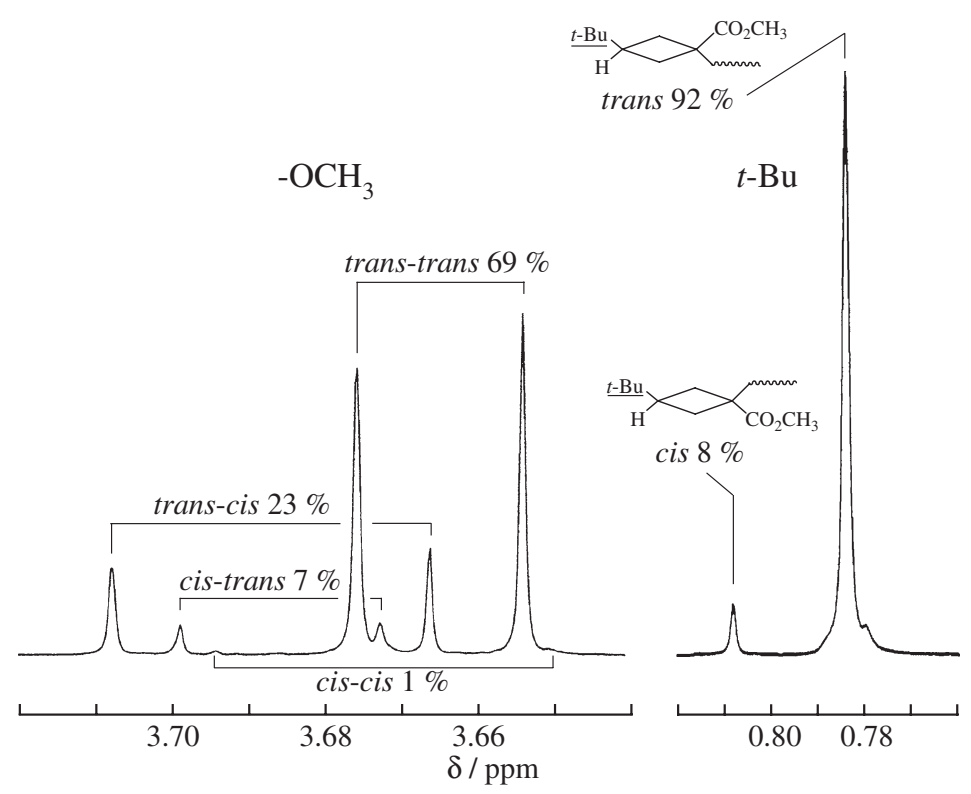

Figure 6. Expanded spectra of $t$ - $\mathrm{Bu}$ and $\mathrm{OCH}_{3}{ }^{1} \mathrm{H}$ NMR signals of fraction $\mathrm{A} 1$.

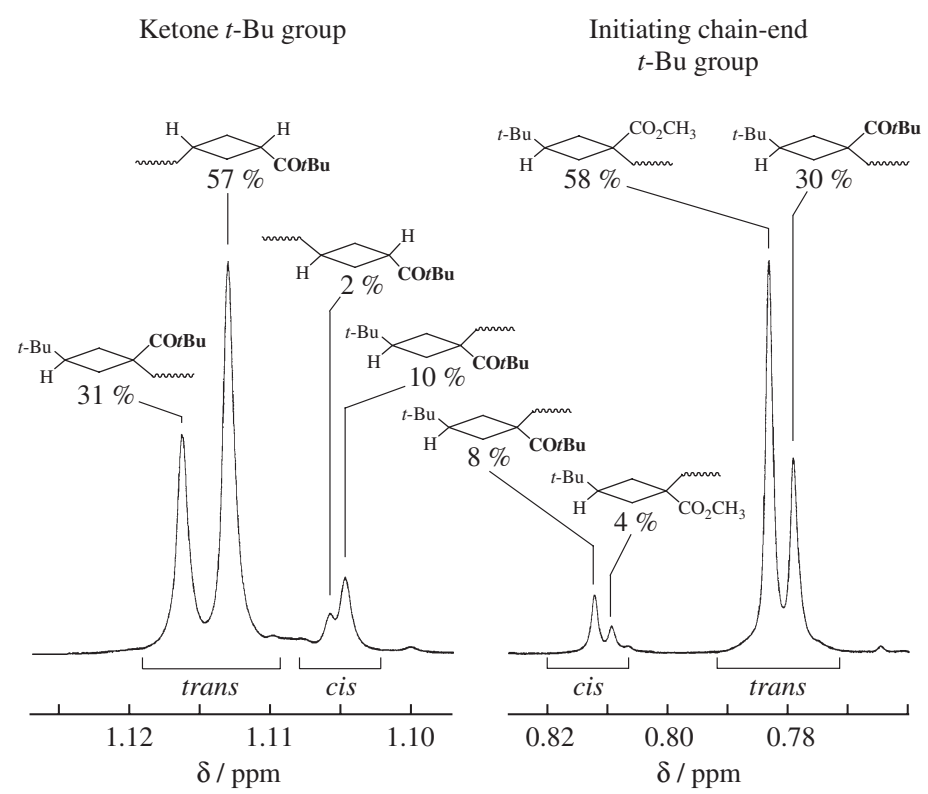

Figure 7. Expanded ${ }^{1} \mathrm{H}$ NMR spectra of fraction A2 at the $t$-Bu group regions (both of initiating chain-end and ketone structure).
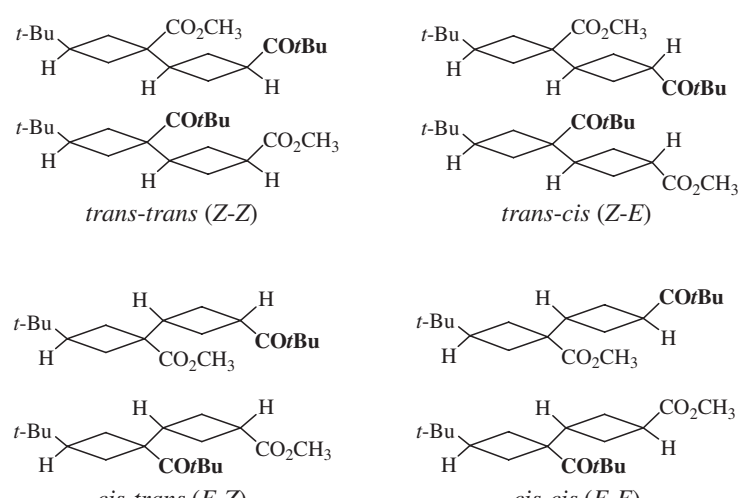

cis-trans $(E-Z)$

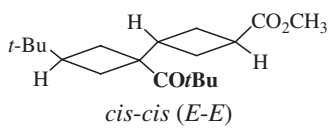

Scheme 4. Eight possible stereoisomers (E,Z-nomenclature). within the cyclobutane ring in the first unit. The further splitting in each peak group (cis or trans) reflects whether the first unit contains the ketone or ester group. The intensity ratio of the two types of terminal methine proton signals $\mathrm{CH}^{e}(2.9 \mathrm{ppm}): \mathrm{CH}^{k}(3.4 \mathrm{ppm})$ was 40:60 (see Figure $3 \mathrm{~b}$ ). The $t$-Bu signal of the ketone structure (1.10-1.12 ppm) also split into four peaks, reflecting cis-trans isomerism in the cyclobutane ring to which the ketone group attaches and the position of the ketone structure, that is, the first or second unit. On the basis of the signal intensities and intensity ratio of the two types of chain-end methine signals, the four peaks are assigned as shown in the figure. The relative intensity of each signal is also in- 


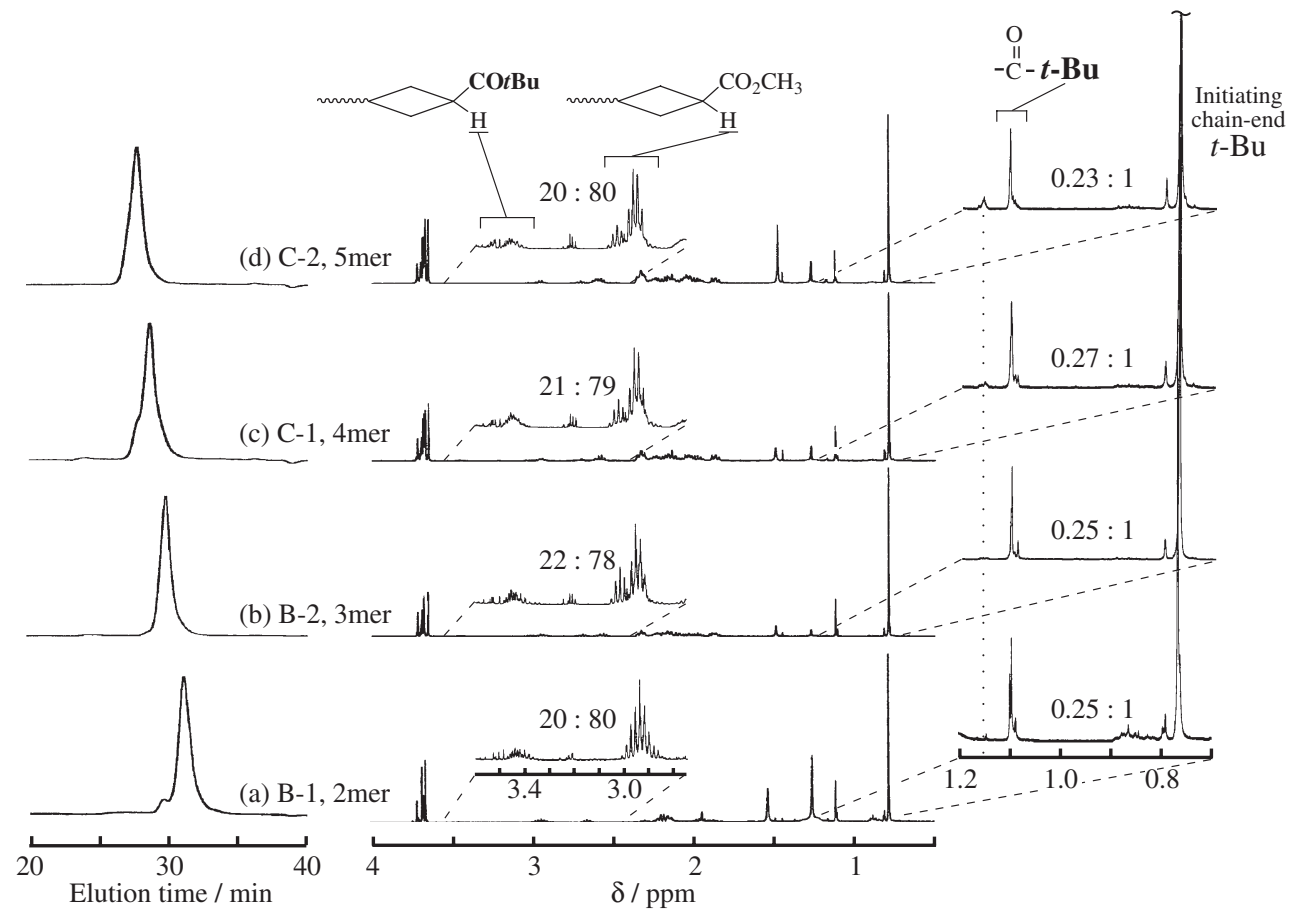

Figure 8. SEC curves (left) and ${ }^{1}$ H NMR spectra (right) of fractions B-1 (a), B-2 (b), C-1 (c) and C-2 (d) in Figure 1.

dicated in the figure. The values suggest that the ketone monomer of trans selectivity in the initiation process is lower than the ester monomer. Moreover, the $t$-Bu signals of initiating chain-end show almost identical chemical shifts and the trans/cis ratio to those for Fraction A1 (see Figure 6).

\section{Other Oligomers}

Furthermore, recycle-SEC was performed also on fractions B and C (Figure 1), to obtain almost unimodal fractions, which were subjected to ${ }^{1} \mathrm{H}$ NMR analysis. Figure 8 shows SEC curves and ${ }^{1} \mathrm{H}$ NMR spectra of the fractionated oligomers. All the fractions show signals at $0.7-0.8 \mathrm{ppm}$ due to the chain-end $t$-Bu groups. From the intensity ratio of the initiating chain-end $t$-Bu signal and aliphatic proton signals, fractions $\mathrm{B}-2, \mathrm{C}-1$ and $\mathrm{C}-2$ were identified as trimer, tetramer, and pentamer, respectively. The fraction B-1 is identical to fraction A in Figure 1a (dimer), which has been confirmed to consist of different types of dimers as described in the previous sections. Every fraction shows signals at $1.1 \mathrm{ppm}$ due to $t$-Bu group in the ketone structure as in the case of the dimer. The intensity ratio of the $t$ - $\mathrm{Bu}$ protons of the initiating chain-end and ketone structure is 1 to 0.25 in the whole dimer (Figure 8a). The values for trimer, tetramer and pentamer are almost the same as the dimer. On the other hand, the ratio of the two types of terminal chain-end methines (ketone and ester) is also almost constant as 20 to 80 ; that is, $20 \%$ of the oligomer molecules contain the cyclobutane unit with $t$ - $\mathrm{Bu}$ ketone group at the terminal chain-end. Since the $t$-Bu ketone exists in almost $25 \%$ of the oligomer molecules, most of the ketone structure $(\sim 80 \%)$ is located at the terminal unit.

As described in the previous section, the initiating chain-end $t$-Bu signal shows splitting due to the cistrans isomerism in the first monomer units. The trans: cis ratios are almost constant for all the oligomers $(92: 8)$ as shown in Figure 8. From the analysis of fraction A2 (see Figure 7), if the ketone unit locates at the first monomeric unit, the initiating $t$-Bu group signals should show splittings. The higher oligomers scarcely exhibit such splittings, suggesting that the initiation reaction involves mostly the attack of $t$-BuLi to $\mathrm{MBCB}$ and not to the ketonic monomer at least under the oligomerization condition ([MBCB $]_{0} /[t-\mathrm{BuLi}]_{0} /$ $\left[\mathrm{Et}(\mathrm{ODBP})_{2}\right]_{0}=3 / 1 / 2$.

In the cases of trimer, tetramer and pentamer, there are small signals around $1.16 \mathrm{ppm}$, which may be assigned $t$-Bu protons of the ketone structure in the main-chain. The intensities of the signals increased with increasing degree of polymerization.

\section{End-group Analysis of Poly $(M B C B)$}

Based on the NMR data of the oligomers, the chain-end structure of poly(MBCB) obtained with $t$-BuLi $/ \mathrm{EtAl}(\mathrm{ODBP})_{2} \quad\left([\mathrm{MBCB}]_{0} /[t-\mathrm{BuLi}]_{0} /[\mathrm{EtAl}-\right.$ $\left.(\mathrm{ODBP})_{2}\right]_{0}=30 / 1 / 3$ ) in toluene at $-78^{\circ} \mathrm{C}$ (run 3 in Table I) was investigated by ${ }^{1} \mathrm{H}$ NMR spectroscopy. Figure 9 illustrates ${ }^{1} \mathrm{H}$ NMR spectrum of the poly(MBCB) with the emphasis on end-group signals. The 
Table I. Polymerization of MBCB with $t$-BuLi/EtAl(ODBP) in toluene for $24 \mathrm{~h}^{\mathrm{a}}$

\begin{tabular}{|c|c|c|c|c|c|c|}
\hline \multirow{2}{*}{ Run } & $\mathrm{Al}$ & Temp. & Yield & \multirow{2}{*}{$\bar{M}_{\mathrm{n}}^{\mathrm{b}}$} & $\bar{M}_{\mathrm{W}}^{\mathrm{b}}$ & trans $^{\mathrm{c}}$ \\
\hline & $\mathrm{Li}$ & ${ }^{\circ} \mathrm{C}$ & $\%$ & & $\bar{M}_{\mathrm{n}}$ & $\%$ \\
\hline 1 & 0 & -78 & 0 & - & - & - \\
\hline 2 & 0.5 & -78 & 35 & 19200 & 1.99 & 92.1 \\
\hline 3 & 1 & -78 & 60 & 16300 & 1.91 & 91.9 \\
\hline 5 & 3 & -95 & 98 & 17700 & 1.85 & 88.1 \\
\hline 6 & 3 & -78 & 100 & 16000 & 2.29 & 91.8 \\
\hline 7 & 3 & -40 & 100 & 14000 & 2.72 & 86.4 \\
\hline 8 & 3 & 0 & 100 & 11100 & 3.04 & 82.2 \\
\hline 9 & 10 & -78 & 100 & 13300 & 3.16 & 82.4 \\
\hline
\end{tabular}

${ }^{\text {a Monomer }} 2 \mathrm{mmol}$, $t$-BuLi $0.07 \mathrm{mmol}$, toluene $1 \mathrm{~mL}$. ${ }^{b}$ Determined by SEC using chloroform as an eluent with calibration using standard PMMA samples. ${ }^{\mathrm{c}}$ Determined from split ${ }^{13} \mathrm{C}$ NMR signals of quaternary carbons. ${ }^{4}$

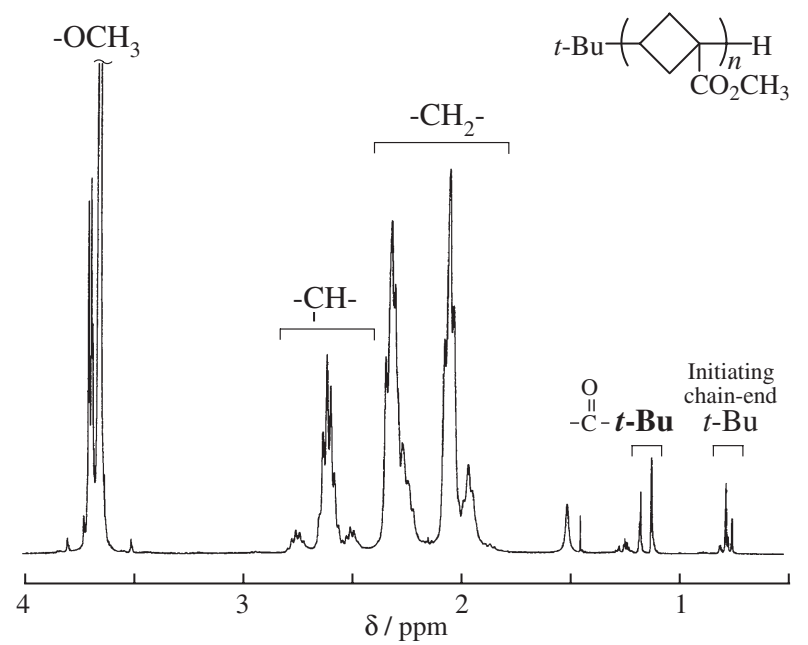

Figure 9. ${ }^{1} \mathrm{H}$ NMR spectrum of poly $(\mathrm{MBCB})$ prepared with $t$-BuLi/EtAl $(\mathrm{ODBP})_{2}(1 / 3)$ in toluene at $-78^{\circ} \mathrm{C}$. The spectrum was measured in chloroform- $d$ at $55^{\circ} \mathrm{C}$.

signals due to $t$-Bu ketone structure are also observed at around $1.1 \mathrm{ppm}$ in addition to the initial $t$-Bu group signals. The results confirm that the formation of the ketone monomer (see Scheme 2) and its participation in the reaction process are not specific to the reaction conditions of the oligomerization but general to the polymerization of $\mathrm{MBCB}$ with $t$ - $\mathrm{BuLi} / \mathrm{EtAl}(\mathrm{ODBP})_{2}$. The integral ratio of the two types of $t$-Bu groups (initiating chain-end and ketone structure) is 1.5 to 1 . In the spectrum of the polymer, the $t$-Bu signals of the ketone structure splits principally into two groups, indicating that the ketone units are embedded at least at two different types of location in the polymer chain.

The effect of the amount of $\operatorname{EtAl}(\mathrm{ODBP})_{2}$ on the chain-end structure of the polymer formed was examined for the polymerization at $-78^{\circ} \mathrm{C}$. The results are summarized in Table I. The polymerization with $t$-BuLi alone did not give any polymeric products

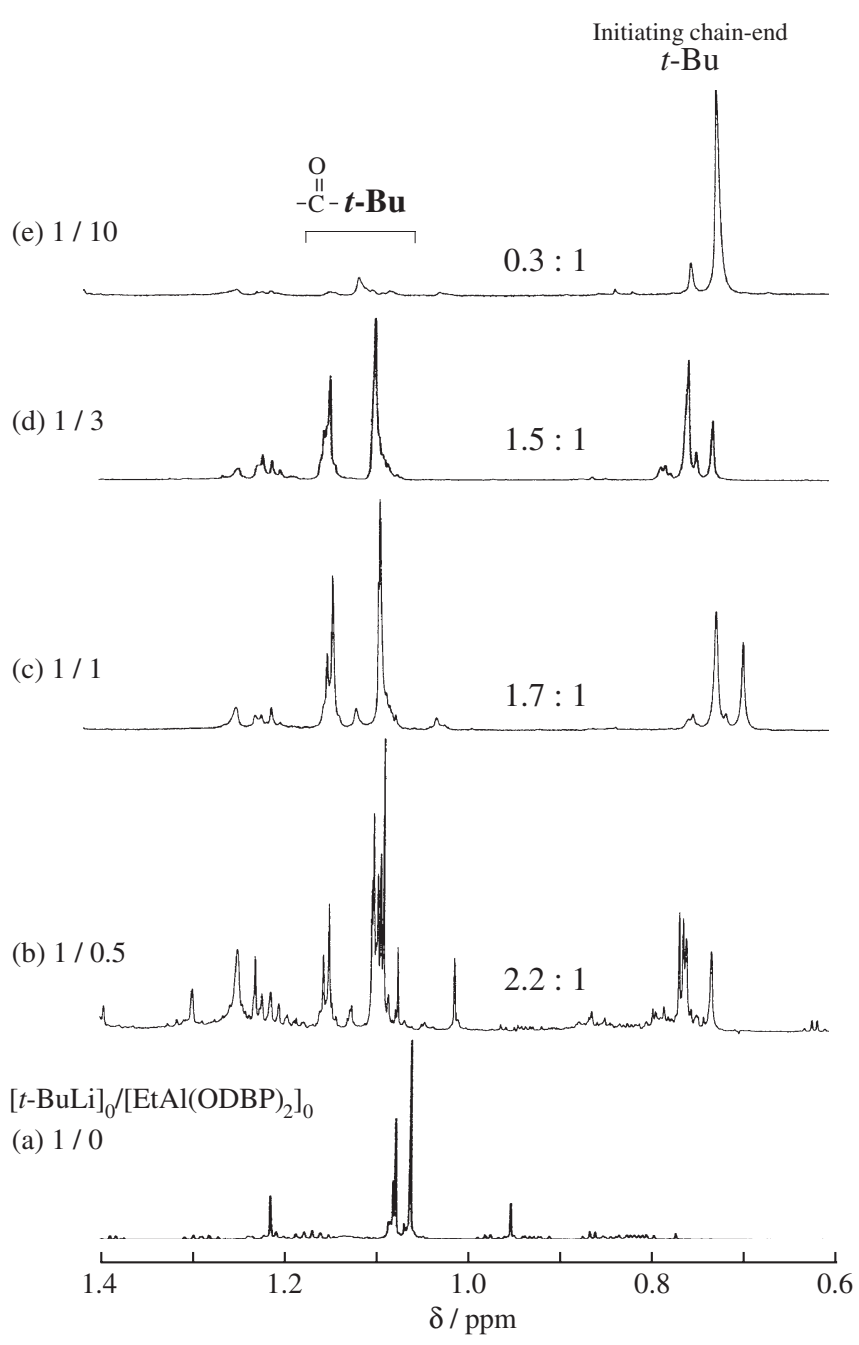

Figure 10. Expanded $t$-Bu group regions of the ${ }^{1} \mathrm{H}$ NMR spectra of poly(MBCB)s prepared with $t$-BuLi/EtAl $(\mathrm{ODBP})_{2}$ at different $[t-\mathrm{BuLi}]_{0} /\left[\mathrm{EtAl}(\mathrm{ODBP})_{2}\right]_{0}$ ratios.

(run 1). In contrast, when $t$-BuLi was used in combination with $\mathrm{EtAl}(\mathrm{ODBP})_{2}$, the polymerization proceeded to form the polymers, the yield of which increased with increasing $\mathrm{Al} / \mathrm{Li}$ ratio (runs 2, 3, 6, 9). The initiator efficiency also became higher as the amount of $\operatorname{EtAl}(\mathrm{ODBP})_{2}$ increased, while the molecular weight distribution of the polymer became broader, and the trans content decreased when the large excess of $\mathrm{EtAl}(\mathrm{ODBP})_{2}$ was employed.

Figure 10 shows the expanded ${ }^{1} \mathrm{H}$ NMR spectra of the reaction products focusing on the $t$-Bu group regions both of initiating chain-end and ketone structure. The product from the reaction with $t$ - $\mathrm{BuLi}$ alone shows the $t$-Bu signal of the ketone structure at 1.06$1.10 \mathrm{ppm}$ but no signal due to the initiating chainend (Figure 10a). The results suggest that, without $\mathrm{EtAl}(\mathrm{ODBP})_{2}$, almost all $t$-BuLi charged is consumed through the carbonyl attack so that the initiation does not take place.

The relative peak intensity of the $t$-Bu group in the 
ketone structure decreases with increasing amount of $\mathrm{EtAl}(\mathrm{ODBP})_{2}$. Thus, $\mathrm{EtAl}(\mathrm{ODBP})_{2}$ is effective in protecting the carbonyl group from the carbonyl attack of $t$-BuLi, leading to the successful initiation. Nevertheless, a part of $t$-BuLi attacks the monomer at the carbonyl group to release the ketone monomer, which is then incorporated into the polymer chains.

The $t$-Bu signals of initiating chain-end in Figure $10 \mathrm{e}\left([t-\mathrm{BuLi}]_{0} /\left[\mathrm{EtAl}(\mathrm{ODBP})_{2}\right]_{0}=1 / 10\right)$ split into two peaks due to cis-trans isomerism as the corresponding signals of Fraction A1 (see Figure 6), suggesting that the initiation takes place through the attack of $t$-BuLi to MBCB almost exclusively. The polymers formed at the $[t-\mathrm{BuLi}]_{0} /\left[\mathrm{EtAl}(\mathrm{ODBP})_{2}\right]_{0}$ ratios of $1 / 3,1 / 1$ and $1 / 0.5$ contain relatively large amounts of the ketone unit and show the initial $t$-Bu group signals with more complicate splittings. The further splits, in addition to cis-trans isomerism, may be due to the location of the $t$-Bu carbonyl group at and/or near the initial monomer unit, as the ${ }^{1} \mathrm{H}$ NMR spectrum of the fractionated dimer indicates (see Figure 7). From the comparison with the NMR spectrum of fraction A2 (see Figure 7), the initial $t$ $\mathrm{Bu}$ group signals observed at higher field (0.72-0.73 ppm) than those observed in Figure 10e may be ascribed to the first unit with the ketone structure attached with the initial $t$-Bu group. Under the oligomerization conditions, the ratio $[\mathrm{MBCB}]_{0} /\left[\mathrm{Et}(\mathrm{ODBP})_{2}\right]_{0}$ was $3 / 2$, which is rather close to the condition for run 9 in Table I ( $c f$. Figure 10e); $[\mathrm{MBCB}]_{0} /\left[\mathrm{Et}(\mathrm{ODBP})_{2}\right]_{0}=$ $3 / 1$. These results imply that, when the amount of $\mathrm{EtAl}(\mathrm{ODBP})_{2}$ is small relative to that of the monomer, the ketone monomer generated by the side reaction is incorporated into the chain even in the early stage of polymerization probably due to higher reactivity of the ketone monomer ${ }^{18}$ and less effective activation of MBCB with the aluminum Lewis acid. ${ }^{19}$

To examine the influence of polymerization temperature, the polymerization of $\mathrm{MBCB}$ with $t$-BuLi/ $\mathrm{EtAl}(\mathrm{ODBP})_{2}(1 / 3)$ was carried out in toluene at several temperatures (Table I runs 5-8). Figure 11 shows the expanded $t$-Bu group regions of ${ }^{1} \mathrm{H}$ NMR spectra of the polymers. The signals due to the $t$-Bu group at the initiating chain-end become more complicated with increasing temperature to show several unassigned peaks. However, the commonly observed signals due to the $t$-Bu group in the ketone structure split into two principal groups, one at $1.14 \mathrm{ppm}$ and the other at $1.09 \mathrm{ppm}$. The former may be assigned to the ketone structure in the main-chain and initiating chain-end units, and the latter to that in the terminating chain-end unit. The intensity of the signals at $1.14 \mathrm{ppm}$ increase with increasing temperature, while those at $1.09 \mathrm{ppm}$ decrease, particularly at $0^{\circ} \mathrm{C}$. In anionic polymerization of vinyl monomers, the reac-
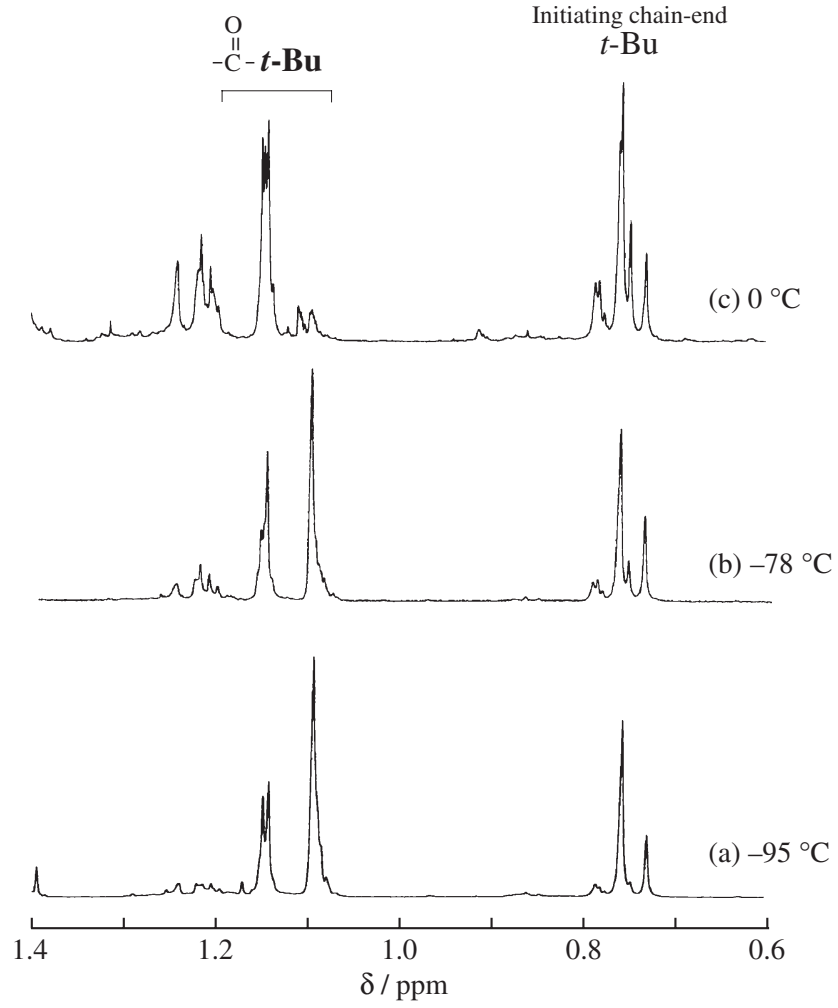

Figure 11. Expanded $t$-Bu group regions of the ${ }^{1} \mathrm{H}$ NMR spectra of poly(MBCB)s prepared with $t$-BuLi/EtAl(ODBP $)_{2}$ $(1 / 3)$ in toluene at several temperatures.

tivity of the monomer having ketonic group is higher than that of the monomer having ester group, and, in contrast, the reactivity of the respective anions formed from these monomers is larger for the ester than for the ketone ${ }^{18}$ If this argument is applicable to the present case, the larger content of the chain-end ketone unit for the polymers formed at lower temperatures may be due to the lower reactivity of the ketone unit anions formed at the propagating chain ends, which fails to propagate further. At $0^{\circ} \mathrm{C}$, the reactivity of the ketone unit anion may be enhanced enough for the polymerization to proceed further so that the ketone unit is embedded within the chain (Scheme 5).

We report here the initiation mechanism of stereospecific polymerization of $\mathrm{MBCB}$ with the combined initiator of $t$-BuLi and $\mathrm{EtAl}(\mathrm{ODBP})_{2}$ in toluene. In order to obtain the information, oligomers of $\mathrm{MBCB}$ were synthesized, fractionated in terms of their degree of polymerization by SEC, and each fraction was characterized by NMR. The oligomers were found to contain the monomeric unit derived from bicyclobutan-1-yl tert-butyl ketone, a product of carbonyl attack of $t$-BuLi to MBCB. The NMR spectroscopic data for the oligomers were also useful for the structural analysis of the polymers, revealing that the ketone was formed under the polymerization conditions and $\mathrm{EtAl}(\mathrm{ODBP})_{2}$ effectively suppresses the carbonyl 


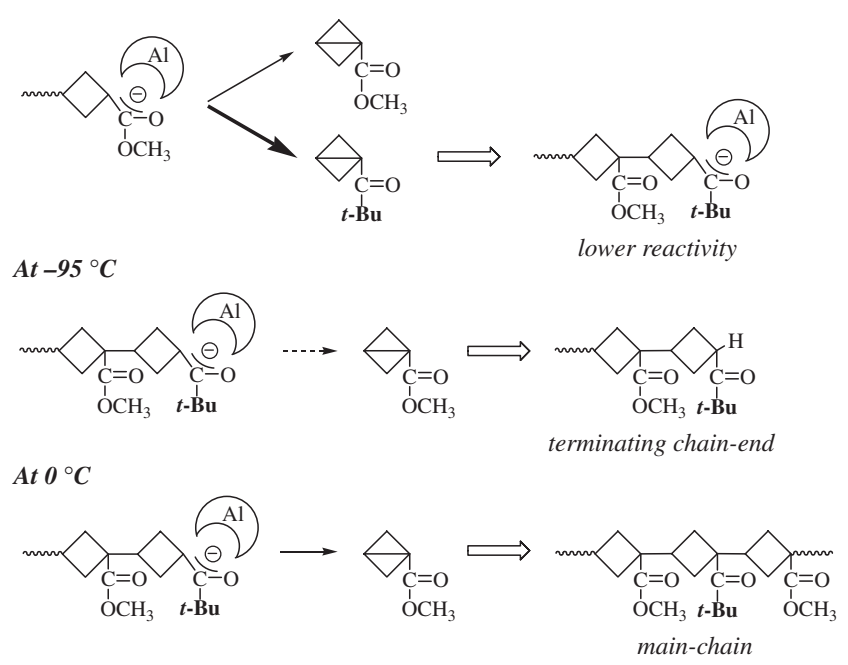

Scheme 5. Possible reaction mechanism involving the ketone monomer at low and high temperatures.

attack of $t$-BuLi probably through coordination to the carbonyl group of $\mathrm{MBCB}$. In the reaction of $\mathrm{MBCB}$ with $t$-BuLi alone, in particular, the carbonyl attack prevails so as to inhibit the initiation reaction, demonstrating the prime importance of the presence of $\mathrm{EtAl}(\mathrm{ODBP})_{2}$. There are ample examples of effective use of bulky aluminum Lewis acids in anionic polymerization of carbonyl-containing monomers, most of which focus on monomer activation and/or stabilization of propagating anions. ${ }^{5-14}$ The present study shed light on the mechanistic aspect of the polymerization, particularly the initiation mechanism, that is influenced by the action of the aluminum Lewis acid.

Acknowledgment. A part of this work was supported by the National Science Foundation under Grant No. 0244260. An additional support by the Petroleum Research Fund administered by the American Chemical Society is also gratefully acknowledged.

\section{REFERENCES}

1. A. B. Padias and H. K. Hall, Jr., in "The Polymeric
Materials Encyclopedia," J. Salamone, Ed., CRC Press, Boca Raton, FL, 1996, p 531.

2. S. W. Choi, W. Yuan, A. B. Padias, and H. K. Hall, Jr., J. Polym. Sci., Polym. Chem. Ed., 37, 1569 (1999).

3. X. Drujon, G. Riess, H. K. Hall, Jr., and A. B. Padias, Macromolecules, 26, 1199 (1993).

4. T. Kitayama, T. Kawauchi, X.-P. Chen, A. B. Padias, and H. K. Hall, Jr., Macromolecules, 35, 3328 (2002).

5. T. Kitayama, Y. Zhang, and K. Hatada, Polym. Bull., 32, 439 (1994).

6. T. Kitayama, Y. Zhang, and K. Hatada, Polym. J., 26, 868 (1994).

7. T. Kitayama, T. Hirano, and K. Hatada, Polym. J., 28, 61 (1996).

8. T. Kitayama, T. Hirano, Y. Zhang, and K. Hatada, Macromol. Symp., 107, 297 (1996).

9. T. Kitayama, T. Hirano, and K. Hatada, Tetrahedron, 53, 15263 (1997).

10. T. Hirano, T. Kitayama, and K. Hatada, Polym. J., 30, 767 (1998).

11. T. Hirano, H. Yamaguchi, T. Kitayama, and K. Hatada, Polym. J., 30, 767 (1998).

12. T. Hirano, T. Kitayama, J. Cao, and K. Hatada, Macromolecules, 33, 1926 (2000).

13. T. Hirano, T. Kitayama, J. Cao, and K. Hatada, Polym. J., 32, 961 (2000).

14. T. Kitayama, M. Tabuchi, and K. Hatada, Polym. J., 32, 796 (2000).

15. H. K. Hall, Jr., C. D. Smith, E. P. Blanchard, Jr., S. C. Cherkofsky, and J. B. Sieja, J. Am. Chem. Soc., 93, 121 (1971).

16. S. C. Watson and J. F. Eastham, J. Organomet. Chem., 9, 165 (1967).

17. K. Maruoka, T. Itoh, K. Sakura, K. Nonoshita, and H. Yamamoto, J. Am. Chem. Soc., 110, 3588 (1988).

18. K. Hatada, T. Kitayama, S. Okahata, and H. Yuki, Polym. J., 13, 1045 (1981).

19. The monomer activation through the coordination with $\mathrm{Et}(\mathrm{ODBP})_{2}$ has been observed in ${ }^{13} \mathrm{C}$ NMR spectra measured in toluene- $d_{8}$ at $-78{ }^{\circ} \mathrm{C}$; the chemical shift of the methine carbon at 3-position changed from $15.8 \mathrm{ppm}$ to 28.2 ppm upon addition of an equimolar amount of $\mathrm{Et}(\mathrm{ODBP})_{2}$, suggesting a decrease of electron density favorable for anionic polymerization, while the carbonyl carbon signal shifted from 172.2 to $181.5 \mathrm{ppm}$. 